\title{
Impact of Outcome-based Histology Laboratory Manual on the Performance of Year I MBBS \\ Students
}

Submitted: 12-06-2018

Accepted: 12-07-2018

Online: 28-09-2018

\author{
Reshma Mohamed Ansari, Atikah Abdul Latiff, Norhafizah AbManan \\ Faculty of Medicine, Cyberjaya University College of Medical Sciences, \\ Cyberjaya, MALAYSIA
}

To cite this article: Mohamed Ansari R, Abdul Latiff A, AbManan N. Impact of outcome-based histology laboratory manual on the performance of year I MBBS students. Education in Medicine Journal. 2018;10(3):23-29. https://doi.org/10.21315/eimj2018.10.3.3

To link to this article: https://doi.org/10.21315/eimj2018.10.3.3

\begin{abstract}
Histology, a branch of anatomy is a correlational science between structure of tissues and their functions. Knowledge of histology is emphasised for undergraduate medical students as a basic for clinical knowledge and research. To impart retainable and reproducible knowledge in histology, a new laboratory manual with images and clinical correlates was introduced to the Year I MBBS students in the Academic Session 2017/2018 during their general anatomy module. The objective structured practical examination marks between 101 students of Batches 2016/17 and 2017/18 were analysed. The difference in marks between both the batches were analysed using SPSS 20. Batch 2017/18 students who used the new lab manual scored better than the previous batch who used the old manual. Independent $t$-test was not statistically significant. The students who used the new manual fared better than their seniors. Since the difference was not statistically significant, it can be concluded that if existent, drawbacks in the lab manual should be improved and adequate usage of the manual by the students should be emphasised. Nevertheless, usage of the new lab manual shows that the students could understand the subject and score better with less study hours.
\end{abstract}

Keywords: Histology, Laboratory manual, Medical education, Anatomy

Reshma Mohamed Ansari, Faculty of Medicine, Cyberjaya University College of Medical Sciences, Persiaran Bestari, Cyber 11, 63000 Cyberjaya, Malaysia | Email: reshmaansari77@gmail.com

\section{INTRODUCTION}

Histology is a branch of anatomy that emphasises on structural organisation of tissues and effectively correlates the structure of the tissues to their diverse physiological function (1). A sound knowledge of histology is essential in medical training and for continuing education (2). Histology is an indispensable science which provides new findings in clinical medicine and research. It forms the basis for identifying abnormalities to confirm the diagnosis and assess the prognosis (1). Research has proved that in most of the invasive carcinomas, one of the most influential predictive factors is histological grading. This emphasises on the accurate reading of histological changes in tissues for potential doctors (1).

With the introduction of new subjects and with expansion of the currently taught curriculum, medical education is faced with the laborious task of reducing the contact hours facilitating independent learning, 
decrease of factual material and increase in teaching of concepts $(3,4)$. Less facultyintensive teaching is employed in premier research universities which has encouraged independent learning among students (5). However, the basic concepts of teaching and learning based on experience and research should not be compromised (3).

As far as anatomy education is concerned, loss of curriculum hours has resulted in the students having lack of knowledge in anatomical details of tissues and being unaware of the research applications of microscopic anatomy (6). Another challenge faced by the medical educationists and students is the loss of knowledge of basic medical sciences and even if retained, this knowledge is not integrated into the clinical sciences effectively (7).

Teaching of histology in Malaysian medical schools is a part of anatomy, the others being gross anatomy and embryology. However, not much of literature is available regarding the teaching of the same. The data available on anatomy teaching in Universiti Sains Malaysia (USM) was published in 2007 (8). The teaching learning activities included lecturers, problem based learning, and histology laboratory sessions. Labs are equipped with teaching microscopes and image analysers intended for usage in both teaching and research (8).

In Cyberjaya University College of Medical Sciences (CUCMS), histology is taught by anatomists. The curriculum has histology lectures and histology laboratory sessions. The lab sessions are supplemented with a manual to take note of the structures to be viewed. The students are expected to complete the manual which could be used as a learning material for the future. The lab manuals are then evaluated by the anatomy discipline members. This approach was considered very cumbersome and the students had difficulty in completing the manual. The students were unable to draw perfectly and this led to gross mistakes in the drawings and some drawings were beyond decipherable. This culminated in lack of interest by the students to use the lab manual for revision during their exams which beat the very purpose of the manual per se. This also contradicted with the revised curriculum which emphasises on reduced student contact hours and studentcentred teaching learning.

Hence our anatomy lecturers came out with a new manual which had incorporated histological images from online university websites, Google, and books with added relevant clinical correlates. In order to test the effectiveness of the current lab manual, the performance of the students in the final practical examination was evaluated and compared with their senior batch who used the old lab manual.

\section{MATERIALS AND METHODS}

There were 101 students of two consecutive MBBS batches (Academic Session 2016/17 and 2017/18) studying in CUCMS and they were selected for this quasi experimental study. Data in the form of marks was taken from all the students without randomisation of the students. Students from both batches had the same entry requirements for foundation (minimum of 5 B's in SPM and $\mathrm{O}$ levels in science subjects) which made up around $80 \%$ of the MBBS students. Eligible students with A-levels, Matriculation, and foundation from other institutions comprised the $20 \%$ of the intake for MBBS. The study was done during the General Anatomy module which is a compulsory course in the first semester of MBBS. Both the batches were taught by qualified anatomists. The students were expected to complete three lab manuals for three laboratory sessions during this module. The students who underwent this module in $2016 / 17$ used the old version of the lab manual in which the students had to draw the histological images of the structures they viewed in the lab session.

The new lab manual was prepared for the Academic Session 2017/2018, bearing the disadvantages of the earlier one in mind. 
Images obtained from textbooks and online university websites were incorporated into the manual to be labelled by the students. Clinical correlates were added in an attempt correlate the knowledge of histology with histopathology. The manual was vetted among the members of anatomy discipline to maintain the utmost standard and to ensure that the learning objectives specified in the course outline were adequately met. These manuals were also used for the three lab sessions during general anatomy and the students' responses were evaluated by the lecturers.

For both batches, pre-lab presentation and interactive lectures were given to facilitate the process of slide reading by students. During laboratory sessions, the lecturers demonstrated the identifiable features of the slides and the artefacts to be avoided. Then the students were asked to view the slides and work on their own to identify the features which were highlighted in the learning objectives. Students in Batch 2016/17 drew the images and labelled the parts on their own. In contrast, the students of Batch 2017/18 labelled the images provided in the lab manual according to their viewing and understanding. Every student had the opportunity to come to a conclusion regarding the structure of the tissue, share it with their peers and discuss their findings with the laboratory instructors. The anatomy discipline members then reviewed the lab manuals and gave comments wherever necessary.

Objective Structured Practical Examination (OSPE) which covered basic cell and tissue concepts was conducted in 2017 and 2018 following the general anatomy module as a component of the block's end of course examination. The blueprint of both the exams were similar and was approved by the course committee. OSPE during both years had 15 histology stations, comprising of two marks per station. The questions were vetted by the course committee comprising of the anatomy lecturers. Following vetting, the questions were checked and approved by the deputy dean of academic affairs. During the practical exam the slides were projected on Leica microscopes. Each student was given two minutes for each station to answer two questions on the mounted slide. The students were required to identify the slide and answer a question on the same. The responses were written on the provided answer sheets. The answer scripts were then hand-graded by the lecturers. The marks from OSPE of both batches were analysed using SPSS Version 20.

\section{RESULTS}

The demographic details of the 2016/17 and 2017/18 batches are presented in Table 1. The data acquired was of normal distribution. The mean difference between both batches was found to be -1.19 (CI -2.54 to 0.15 ). Figure 1 depicts the difference in mean between the marks of two batches with students in Batch 2017/18 scoring slightly higher mark compared to students in Batch 2017/18. Table 2 shows the mean difference of 1.19 mark. The results were analysed using SPSS Version 20. Independent $t$-test was applied to compare the mean difference. The results showed that the difference was not statistically significant as the $p$ value was less than 0.05 .

\section{DISCUSSION}

In our study, the comparison between the OSPE marks between the two batches, shows that the batch who learned and practised histology with the new module had higher marks compared to the previous batch. This demonstrates higher chance of using the manual as a reference during exams or otherwise. Though the difference in marks between batches was not statistically significant, the factors made easy with the new lab manual were remarkable. However, the results cannot be generalised as the population is not randomised and the results depend on internal validity. The amount of work hours of the student and the time taken for the lecturer to evaluate 
the lab manual had reduced considerably which compels us to update the manual and use it as an effective learning tool.

\section{Evolution of Histology Teaching in Medical Schools}

The traditional method of teaching histology consisted of didactic lectures and viewing the slides in the lab using microscopes (1).
Though teaching of histology has not been changed over the past century, currently virtual microscopy and online histology materials are considered as a giant leap in histology teaching (9). Histology teaching is currently tailored to the learning styles of the current generation, with more emphasis placed on the self-learning of the students and the correlation of their basic sciences knowledge with the clinical

Table 1: The demographic data of the study population

\begin{tabular}{llcc}
\hline & & Batch 2016/17 & Batch 2017/18 \\
\hline Age & & $19-25$ years & $19-25$ years \\
Gender & Male & $34(34 \%)$ & $31(31 \%)$ \\
& Female & $67(66 \%)$ & $70(69 \%)$ \\
Race & Malay & $94(93 \%)$ & $75(74 \%)$ \\
& Indian & $6(6 \%)$ & $9(9 \%)$ \\
& Chinese & 0 & $8(8 \%)$ \\
& Others & $1(1 \%)$ & $9(9 \%)$ \\
\hline
\end{tabular}

Note: *Others include international students and students from East Malaysia.

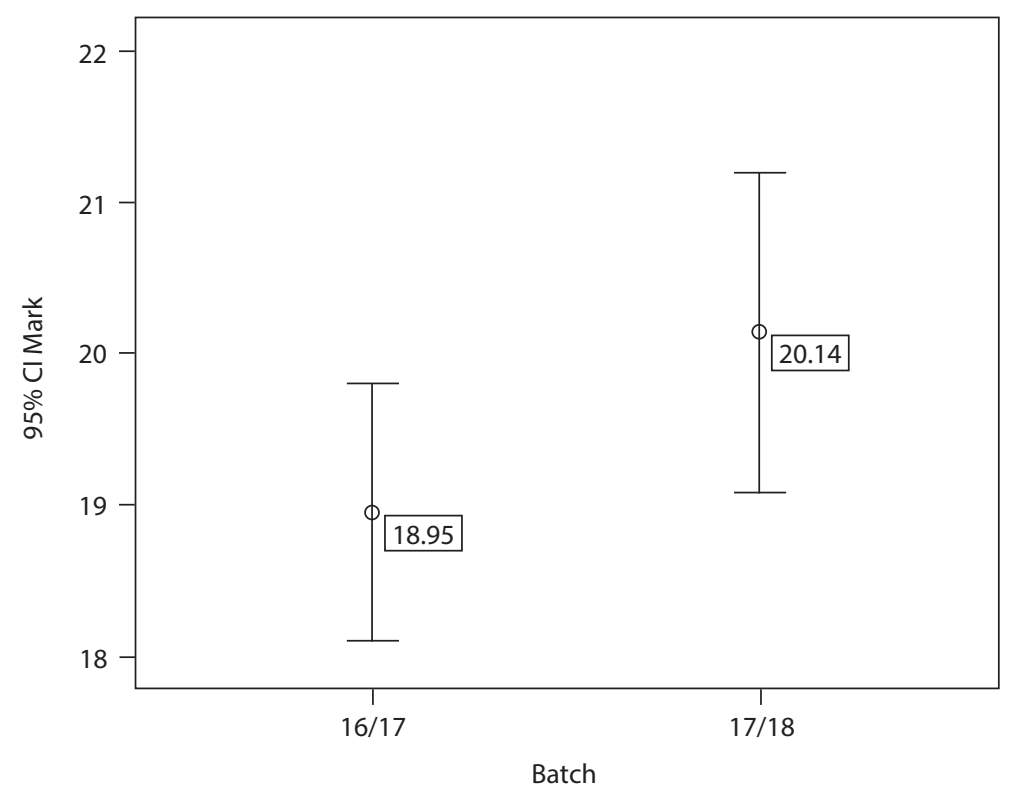

Figure 1: The difference in mean between both batches.

Table 2: Mean difference between marks of Batches 2016/17 and 2017/18

\begin{tabular}{ccccc}
\hline Batch & N & Mean (SD) & Mean difference (CI) & P value \\
\hline $2016 / 17$ & 101 & $18.95(4.29)$ & -1.19 & 0.082 \\
$2017 / 18$ & 101 & $20.14(5.36)$ & $(-2.54$ to 0.15$)$ & \\
\hline
\end{tabular}


scenarios (1). Many medical schools employ a combination of traditional and virtual microscopy for teaching histology (1) and some medical schools use virtual microscopy only (10). Though virtual microscopy is fast taking over conventional microscopic slide teaching, histologists still ascertain the use of traditional lab practice for medical students (11). Competing pressure in curricula influences histology teaching time which has drastically reduced the classroom time dedicated for histology (9). Similarly, there has been a concurrent reduction in the laboratory teaching time of histology too (1). The programme learning outcomes encourage students to be taught to read slides rather than memorise them (12). The less time allocated for histology has seen its ripple effects in pathology and residency. However, since residency is too late for a remedial to be given, efforts must be taken to reduce the knowledge gap in the earlier stages of medical school itself (9).

Abnormalities in the tissue can be better understood and explained by the students, can be achieved only with the appreciation of normal tissue as emphasised by teachers of both histology and histopathology (3). Histology knowledge and lab practice should be well enough to apply the concepts in histopathology and clinical scenarios (6). Researchers have suggested that initial learning is vital for better retention and hence elements of a course that promote better understanding and focus on the meaning of the course rather than memorisation is more effective. Emphasis has also been placed on provision for adequate time to learn complex materials and effective engagement with the practice (7).

\section{Challenge Faced by Educators}

The challenge is imparting knowledge through the involvement of experienced medical educators and reaping the benefits of learning in a small group environment, even when the exercise is given within a large learning space (13). Hence universities which intend to reduce the face to face learning time of students, insists on providing a take home material for the students to practice adequately and then discuss their findings amongst peer groups (1).

The lab manual is a form of assessment, grading and reporting where the students demonstrate their knowledge (1). Technology has offered us the chance to develop new interactive educational resources to achieve our didactic objectives (14). A well prepared lab manual facilitates effective revision for the students during preparation for exam (15). Incorporation of questions and clinical correlates in the lab manual facilitates better understanding. This also enables the faculty to measure the outcomes by setting testable questions for the OSPE (6).

\section{Usage of Laboratory Manuals in Various Medical Schools}

In the current scenario, the number of online images available these days with extensive labelling has created an opportunity for creating new ways to help students learn and retain knowledge (9). Students learning histology are given a normal photomicrograph of any structure and quizzed on the key features that have allowed them to identify the structure (9). University of South Wales uses the integrated approach for teaching histology which employs worksheets with defined learning objectives specifically tailored for deeper understanding of the subject (3). The worksheets provide a framework and images akin to the slides for better understanding and interpretation (3). Working out these modules either independently or in groups during class provides a platform for effective discussion and reflection of the knowledge the students acquire (3). The worksheets also emphasise the interpretation of histology rather than detailed knowledge of the histological features themselves (3). Evidence also suggests that by providing worksheets the 
students willingly engaged in active and independent learning during lab sessions and found in depth understanding with team work (3). An effective histology manual designed by the Department of Anatomy, Postgraduate Institute of Medical Sciences, Rohtak, India, includes a list of slides, learning objectives and the important identification features of every slide (15). Since our manual satisfies the learning styles of the current generation, it would be a useful tool for teaching-learning.

\section{Traditional vs Modern Curriculum}

In the traditional curriculum, during laboratory sessions the students were divided in small groups to view the slides to ensure team work and acquisition of knowledge in the usage of binocular microscopes (2). The manual used for the laboratory sessions provided the students an index of the structures to be viewed during the sessions. The students had to complete the manual independently which could be used for revision purposes. Earlier, students were asked to draw the structures they viewed, in the practical manual. This placed a strain on the students who were not artistically inclined, requiring needless hours of labour to draw clear images. Unclear drawings were of no use to the students during revision for exams. Moreover, they were considered useless for integration of histology with clinical knowledge (12).

Currently, the students who are subjected to virtual histology lose the three dimensional viewing of the slides (14). Moreover virtual histology requires a high degree of technical support which is financially draining and unaffordable for most of the institutions (1). It has been found out that the students do not wish to rely totally on the electronic source as they still find the traditional curriculum a matter of convenience (14). The teachers of virtual histology almost always include a laboratory assignment or manual for class after-class work to gauge the depth of understanding in students (14). The current lab manual used in CUCMS is midway between the traditional and modern curriculum and it is in consensus with the competency based curriculum. It has been designed for increased retaining, giving less labour to students and avoiding subjective assessment.

\section{CONCLUSION}

It can be concluded that the batch that used the new laboratory manual had scored marginally higher than the previous batch. However, the result being statistically insignificant necessitates further improvement in the manual and ensuring adequate student participation.

\section{RECOMMENDATION}

The future lies in integration of clinical medicine with basic medical sciences especially histology and histopathology (1). This can be done by introducing cases alongside histology images for a better integration (1). Medical book publishers may provide supplementary digital materials to support their hard cover histology textbooks (2). A study to evaluate the prospect of virtual histology in Malaysian setup and integration between histology and histopathology are seen as future topics of interests.

\section{REFERENCES}

1. Hussein I, Raad M, Safa R, Jurjus RA, Jurjus A. Once upon a microscopic slide: the story of histology. J Cytol Histol. 2015;6(6):1-4. https://doi.org/10.4172/2157-7099.1000377

2. Paulsen FP, Eichhorn $M$, Bräuer L. Virtual microscopy - the future of teaching histology in the medical curriculum? Ann Anat. 2010;192(6):378-82. https://doi.org/ 10.1016/j.aanat.2010.09.008 
3. Kumar RK, Freeman B, Velan GM, De Permentier PJ. Integrating histology and histopathology teaching in practical classes using virtual slides. Anat Rec. 2006;289(4):128-33. https://doi.org/10.1002/ ar.b.20105

4. Drake RL. Anatomy education in a changing medical curriculum. J Anat. 1999;74(4):487-90.

5. Bloodgood RA, Ogilvie RW. Trends in histology laboratory teaching in United States medical schools. Anat Rec. 2006;289(5):169-75. https://doi.org/10.1002/ ar.b.20111

6. Heidger PM, Dee F, Consoer D, Leaven T, Duncan J, Kreiter C. Integrated approach to teaching and testing in histology with real and virtual imaging. Anat Rec. 2002;269(2):107-12. https://doi. org/10.1002/ar.10078

7. Marcel FD. Knowledge loss of medical students on first year basic science courses at the University of Saskatchewan. BMC Med Educ. 2006;6(1):5. https://doi.org/ 10.1186/1472-6920-6-5

8. Aziz N, Asari MA, Aziz RN. Teaching of anatomy in an integrated teaching based curriculum at the University Science Malaysia. Pak J Med Health Sci. 2007;1(4):131-33.

9. Parker EU, Reder NP, Glasser D, Henriksen J, Kilgore MR, Rendi MH. NDER: a novel web application for teaching histology to medical students. Acad Pathol. 2017;4:1-5. https://doi.org/10.1177/2374289517691061
10. Harris $T$, Leaven $T$, Heidger $P$, Kreiter C, Duncan J, Dick F. Comparison of a virtual microscope laboratory to a regular microscope laboratory for teaching histology. Anat Rec. 2001;265(1):10-4. https://doi.org/ 10.1002/ar.1036

11. Drake RL, Lowrie DJ, Prewitt CM. Survey of gross anatomy, microscopic anatomy, neuroscience, and embryology courses in medical school curricula in the United States. Anat Rec. 2002;269(2):118-22. https://doi.org/10.1002/ar.10079

12. Cotter JR. Laboratory instruction in histology at the University at Buffalo: recent replacement of microscope exercises with computer applications. Anat Rec. 2001;265(5):212-21. https://doi.org/10.1002/ ar. 10010

13. Bloodgood RA. Active learning: a small group histology laboratory exercise in a whole class setting utilizing virtual slides and peer education. Anat Sci Edu. 2012;5(6):367-73. https://doi.org/10.1002/ ase. 1294

14. Hortsch M. Virtual biology: teaching histology in the age of Facebook. FASEB J. 2013;27(2):411-13. https://doi.org/10.1096/ fj.13-0201ufm

15. Gupta G, Sudha Chhabra KS. Innovative method of teaching histology. Int J Rec Ad Pharm Res. 2012;2(1):33-6. 